\title{
The protective effect and mechanism of epidermal growth factor on necrotizing enterocolitis in a neonatal rat model
}

\author{
Wenqian Chen ${ }^{1}$, Changyi Yang ${ }^{1}$, Heng Xue ${ }^{2}$, Qi Huang ${ }^{1}$ \\ ${ }^{1}$ Department of Neonatology, Fujian Maternity and Child Health Hospital, Affiliated Hospital of Fujian Medical University, Fuzhou, China; \\ ${ }^{2}$ Department of Laboratory Medicine, Fujian Maternity and Child Health Hospital, Affiliated Hospital of Fujian Medical University, Fuzhou, China \\ Contributions: (I) Conception and design: W Chen; (II) Administrative support: C Yang; (III) Provision of study materials or patients: W Chen, H \\ Xue; (IV) Collection and assembly of data: W Chen, Q Huang; (V) Data analysis and interpretation: W Chen, H Xue, Q Huang; (VI) Manuscript \\ writing: All authors; (VII) Final approval of manuscript: All authors. \\ Correspondence to: Wenqian Chen, MM. No.18 Daoshan Road, Gulou District, Fuzhou 350001, China. Email: chwenqian1984@163.com.
}

\begin{abstract}
Background: Necrotizing enterocolitis (NEC) is the most common acquired gastrointestinal emergency in premature infants. This study aimed to investigate the protective effect and mechanism of epidermal growth factor (EGF) on NEC in a neonatal rat model.

Methods: We randomly divided 50 newborn SD rats into a control group, NEC group, NEC $+50 \mathrm{ng} / \mathrm{mL}$ EGF group, NEC + $500 \mathrm{ng} / \mathrm{mL}$ EGF group, and NEC + 1,000 ng/mL EGF group, with 10 cases in each group. The appearance of intestinal tissue, physiological status score, inflammatory factor level, HE staining, and pathological score were used to evaluate the protective effect. A one $\mathrm{cm}$ tissue sample from the proximal ileum of the ileocecal area of five rats from the NEC group and the group that showed a significant protective effect were extracted for transcriptome sequencing.

Results: The levels of IL- $1 \beta$ and IL-6 in the intestinal mucosa in the NEC $+500 \mathrm{ng} / \mathrm{mL}$ EGF group were significantly lower than those in the $\mathrm{NEC}+1,000 \mathrm{ng} / \mathrm{mL}$ EGF group $(\mathrm{P}<0.05)$. Transcriptome sequencing suggested that EGF effects the intestinal barrier, apoptosis, and inflammation of the NEC intestine.

Conclusions: We conclude that the oral administration of $500 \mathrm{ng} / \mathrm{mL}$ EGF effectively inhibits intestinal inflammation in NEC neonatal rat models, thereby affecting the barrier function of the intestinal tract.
\end{abstract}

Keywords: Necrotizing enterocolitis; epidermal growth factor; drug dose; intestinal inflammation

Submitted Jan 28, 2021. Accepted for publication Apr 21, 2021.

doi: $10.21037 / \mathrm{tp}-21-81$

View this article at: http://dx.doi.org/10.21037/tp-21-81

\section{Introduction}

Necrotizing enterocolitis (NEC) is the most common acquired gastrointestinal emergency in premature infants (1) and remains a leading cause of morbidity and mortality in preterm infants (2). According to National Institute of Child Health and Human Development (NICHD) statistics, the incidence of NEC in live births is $0.5-5 \%$ which accounts for 2-5\% of children in the Neonatal Intensive Care Unit (NICU). In addition, more than $90 \%$ of cases are premature infants and the prevalence of very low birth weight infants accounts for $7-10 \%$ (3). Due to a lack of effective prevention and treatment methods, the mortality and sequelae of NEC have remained high. The mortality rate of NEC accounts for $23-30 \%$ of the morbidity, $12-35 \%$ of patients undergo surgery and have bowel stenosis, $20-35 \%$ have short bowel syndrome, and 30-50\% have neurological sequelae (4). The pathophysiology of NEC sees a disruption of the epithelial barrier, which allows luminal bacteria to translocate and trigger a systemic inflammatory response, sepsis, multiple organ failure, and death (4). Although research on the pathogenesis of NEC is longstanding, the exact mechanisms involved remain unclear (5), although premature birth, feeding methods, intestinal flora, infection, genetic susceptibility, and other factors are considered to be the main factors related to its onset (6-8).

The clinical treatment of NEC mainly includes fasting, 
gastrointestinal decompression when necessary, nutritional support, anti-infection measures, maintenance of internal environment stability, and active surgical intervention when conservative medical treatment fails (5). Obviously, the effect of clinical treatment is not ideal (9). In recent years, some new ideas and attempts have been proposed in the treatment of NEC in animal models, such as fecal bacterial transplantation (10), stem cell transplantation (11), and immunotherapy (development of its Toll-recipient) (12), some of which may have good prospects. Studies have found that breastfeeding can reduce the incidence of NEC (13), and growth factor substances in breast milk may be the main components of intestinal protection (14). Epidermal growth factor (EGF) is an important member of the growth factor family, which is secreted into the intestinal lumen by salivary glands, Brenner glands of the duodenum, and Paneth cells of the small intestine. Good et al. (14) found that growth factors substances in breast milk, such as EGF and heparin binding-epidermal growth factor (HB-EGF), can reduce the occurrence and development of NEC and provide new ideas for its prevention. However, the use and dosage of EGF in the prevention of NEC is uncertain, which limits its application in clinical practice. Studies have shown that EGF has the function of protecting the intestinal barrier and inhibiting intestinal epithelial apoptosis and inflammation (15-17). Sullivan et al. $(18,19)$ found that EGF could promote NEC intestinal tissue repair and Isani et al. (20) added EGF to the NEC mouse model and effectively reduced its incidence and the severity of intestinal tissue damage. However, the mechanism of the intestinal protective effect of EGF on NEC is still unclear. Therefore, it is necessary and meaningful to explore the effect and mechanism of EGF in protecting the intestine in NEC in a rat model.

In this study we clarified the protective effect of EGF on the intestine of the NEC rat model and explored the appropriate dose and mechanism of EGF on protecting the intestine by high-throughput transcriptome sequencing. This study provides a theoretical basis for the future clinical application of EGF.

We present the following article in accordance with the ARRIVE reporting checklist (available at http://dx.doi. org/10.21037/tp-21-81).

\section{Methods}

\section{Research objects}

\section{Preparation of newborn rats}

We obtained 45 clean adult SD rats from the Fuzhou
Xingnan Experimental Animal Studio, animal license number: SCXK (Fujian) 2016-0002, of which 30 were female (weight 390 to $420 \mathrm{~g}$ ) and 15 were male (weight 225-260 g). The rats were mated in a cage from 20:00 to 21:00 at the ratio of male to female 1:2. The vaginal plugs were observed from 8:00 to 9:00 on the next day, and six female rats tested positive for vaginal plugs, indicating they had conceived successfully. These were then transferred to another cage and recorded as being at 0.5 days of pregnancy. At 21.5 days of pregnancy, anesthesia was performed for cesarean section with ether, and a total of 57 newborn rats were removed.

\section{Building of NEC model}

The newborn rats were first placed in a hypoxic box containing $100 \%$ nitrogen for 90 seconds then immediately taken out and placed in a refrigerator at $4{ }^{\circ} \mathrm{C}$ for 10 minutes, and then returned to the cage for artificial feeding. Hypoxia-cold stimulation was performed every 12 hours for 3 consecutive days.

\section{Grouping and feeding of newborn rats}

Fifty newborn rats were randomly selected according to the random number table and randomly divided into five groups: a control group, NEC group, NEC $+50 \mathrm{ng} / \mathrm{mL}$ EGF group, NEC + $500 \mathrm{ng} / \mathrm{mL}$ EGF group, and NEC + $1,000 \mathrm{ng} / \mathrm{mL}$ EGF group.

The control group $(\mathrm{n}=10)$ were fed with Rat milk substitute (Borden, USA, PetAg PetLac). The milk was opened 30 minutes after birth and the rats fed with a dropper. The initial amount was $0.2 \mathrm{~mL} / 4 \mathrm{~h}$, which was increased by $0.05 \mathrm{~mL}$ every 12 hours, and the maximum amount was $0.3 \mathrm{~mL} / 4 \mathrm{~h}$. No intervention or stimulation was given. In the NEC group $(n=10)$ the method was the same as that of the control group, and modeling began 48 hours after birth. In the NEC+50 ng/mL EGF group $(\mathrm{n}=10), 50$ $\mathrm{ng} / \mathrm{mL}$ rat epidermal growth factor (Peprotech, Inc., US: $100 \mu \mathrm{g})$ was added to the rat milk substitute, and modeling began $48 \mathrm{~h}$ after birth, and in the NEC + $500 \mathrm{ng} / \mathrm{mL}$ EGF group $(\mathrm{n}=10), 500 \mathrm{ng} / \mathrm{mL}$ rat epidermal growth factor was added to the rat milk substitute, and modeling began $48 \mathrm{~h}$ after birth. Finally, in the NEC $+1,000 \mathrm{ng} / \mathrm{mL}$ EGF group $(\mathrm{n}=10)$, $1,000 \mathrm{ng} / \mathrm{mL}$ rat epidermal growth factor was added to the rat milk substitute, and modeling began $48 \mathrm{~h}$ after birth.

Newborn rats were fed in groups as described above after birth, and the test started 48 hours after birth.

\section{Compliance with Ethical Standards}

This study was performed according to international, 
national, and institutional rules considering animal experiments, clinical studies, and biodiversity rights. The study protocol was approved by the Ethics Committee of the Fujian Maternity and Child Health Hospital (EC Certificate No. 2018-195).

\section{Intestine assessment}

\section{Physiological status}

After the last hypoxia-cold stimulation and before sacrifice, the physiological status of the rats was scored by observing the following: (I) general appearance $(0=$ moisturized and adequately hydrated; $1=$ slightly weak but still moisturized and adequately hydrated; $2=$ very thin and skinny, loose skin and dehydrated; $3=$ wheezing and pain); (II) response to touch $(0=$ normal movement in the cage; $1=$ twisting when supine; $2=$ no twisting when supine; $3=$ motionless limbs and lying down); (III) natural activities $(0=$ alert (no stimulus); $1=$ respond to slight stimuli; $2=$ respond to strong stimuli; $3=$ no response to strong stimuli); (IV) complexion $(0=$ pink; $1=$ pale (only on the limbs); $2=$ pale (full body); $3=$ grey) (21).

\section{Intestine appearance}

Twenty-four hours after the last hypoxia-cold stimulation, the rats were sacrificed by cervical dislocation on an empty stomach. The small intestine was removed and the appearance of the intestine of each group of rats was then observed.

\section{Intestinal tissue extraction}

The $1 \mathrm{~cm}$ proximal ileum of the blind part was retrieved, fixed in formalin, embedded in paraffin, and stained with hematoxylin and eosin for pathological scoring. In addition, $1 \mathrm{~cm}$ of the proximal ileum from the blind part was retrieved for transcriptome sequencing.

\section{HE staining and pathological score}

A $1-\mathrm{cm}$ section of the terminal ileum adjacent to the ileocecal valve was collected from each rat, then fixed in formalin, embedded in paraffin, and stained with hematoxylin and eosin. The published NEC scoring system was adopted to evaluate pathological changes in the intestine where: $0=$ normal arrangement of villi, complete tissue structure; $1=$ slight villus core separation; $2=$ moderate villus core separation, or mild edema in submucosal and muscular layers; $3=$ region villous sloughing, severe edema in submucosa and muscular layers; and $4=$ loss of villi and bowel necrosis. For more accurate assessment of damage, intermediate scores including $0.5,1.5,2.5$, and 3.5 were also used where necessary. Rats with a pathological score $\geq 2$ were considered to have NEC $(21,22)$. Pathological scoring was performed independently by two examiners in a doubleblind manner, and the average value was taken as the result.

\section{Inflammatory factor levels}

Enzyme-linked immunosorbent assay (ELISA) was used to detect the expression levels of interleukin (IL)-1 $\beta$ and IL-6 in mucosal tissues in vivo (23).

\section{High-throughput transcriptome sequencing}

\section{Sequencing}

Five ileal tissues of the NEC group and NEC $+500 \mathrm{ng} / \mathrm{mL}$ EGF group were subjected to RNA extraction. According to Wang Z's library construction method $(24,25)$, a total of 10 DNA libraries were constructed and sequencing was completed on the sequencing platform BGISEQ-500 (BGI, China). The adapters, unknown deviations, and lowquality fragments in the original sequencing fragments were removed. Following this, valid fragments were generated and compared with the rat transcriptome database (NCBI, reference genome version: GCF_.5_Rnor_6.0).

\section{Analysis of sequencing results}

Differentially expressed genes (DEGs) were analyzed by Gene Ontology (GO) and the Kyoto Encyclopedia of Genes and Genomes (KEGG), and further classified according to the official classification. Transcriptome sequencing was completed by BGI.

\section{Statistical analysis}

Graph Pad Prism 8 software was used for data statistics and mapping. Measurement data that fit the normal distribution were expressed as mean $\pm \mathrm{SE}$, and the differences between groups were first compared using one-way ANOVA, then the pairwise comparison was performed using the Tukey test. For measurement and grade data that did not meet the normal distribution, the median (minimum, maximum) was used. First, the Kruskal-Wallis $\mathrm{H}$ test was used to compare the differences between the groups, then the Dunn test was used in pairwise comparisons. Count data were expressed in number of cases (percentages) and differences between groups were compared using Fisher's exact method. When the $\mathrm{P}$ value was less than 0.05 , the results were considered 
Table 1 Changes in newborn rats weight

\begin{tabular}{lcccc}
\hline Groups & Cases & Birth weight $(\mathrm{g})$ & Terminal weight $(\mathrm{g})$ & Weight change $(\mathrm{g})$ \\
\hline control & 10 & $6.86 \pm 0.43$ & $7.31 \pm 0.70$ & $0.45 \pm 0.71$ \\
NEC & 10 & $6.85 \pm 0.43$ & $5.32 \pm 0.17^{\mathrm{a}}$ & $-1.53 \pm 0.36$ \\
$\mathrm{NEC}+50 \mathrm{ng} / \mathrm{mL}$ EGF & 10 & $6.94 \pm 0.39$ & $5.36 \pm 0.20^{\mathrm{b}}$ & $-1.58 \pm 0.31$ \\
$\mathrm{NEC}+500 \mathrm{ng} / \mathrm{mL}$ EGF & 10 & $6.80 \pm 0.32$ & $6.59 \pm 0.71$ & $-0.21 \pm 0.20$ \\
NEC $+1,000 \mathrm{ng} / \mathrm{mL}$ EGF & 10 & $6.97 \pm 0.47$ & $6.27 \pm 0.74^{\mathrm{c}}$ & $-0.70 \pm 0.70^{\mathrm{d}}$ \\
F value & & 0.594 & 4.561 & 0.035 \\
P value & & 0.484 & 0.021 & 0.035 \\
\hline
\end{tabular}

Data are presented as the mean $\pm \mathrm{SD} .^{\mathrm{a}}$, the terminal weight of rats was significantly lower than birth weight in the NEC group $(\mathrm{P}<0.05) .{ }^{\mathrm{b}}$, the terminal weight of rats was significantly lower than birth weight in the NEC $+50 \mathrm{ng} / \mathrm{mL} E G F$ group $(P<0.05) .^{c}$, the terminal weight of rats was significantly lower than birth weight in the NEC $+1,000 \mathrm{ng} / \mathrm{mL}$ EGF group $(\mathrm{P}<0.05)$. ${ }^{\mathrm{d}}$, the weight loss of the $\mathrm{NEC}+1,000 \mathrm{ng} / \mathrm{mL}$ EGF group was smaller than that of the NEC group and NEC $+50 \mathrm{ng} / \mathrm{mL}$ EGF group $(P<0.01)$. SD, Standard Deviation; NEC, Necrotizing enterocolitis; EGF, epidermal growth factor.

statistically significant.

To perform gene expression analysis, the number of fragments on the alignment was calculated, and RESM software was then used to normalize it to RPKM. The DEseq2 method based on negative binomial distribution was used to analyze the statistical significance of differentially expressed genes (DEGs), and the threshold was set as follows: EGF/NEC expression level $\geq 2.00$, corrected $\mathrm{P}$ value ( $Q$ value $) \leq 0.05(26,27)$. After aligning $D E G$ to $G O$ and KEGG databases, a hypergeometric test was performed, and gene ontology (GO) and KEGG enrichment analysis were further performed on all DEGs. The false discovery rate (FDR) for each $\mathrm{p}$ value was calculated, and FDR $<0.01$ was defined as significant enrichment $(28,29)$.

\section{Results}

\section{Changes of rats in initial and terminal weight}

The birth weight of newborn rats in each group was balanced, and there was no significant difference between the groups. The terminal weight of rats was not significantly different from birth weight in the control group and the $\mathrm{NEC}+500 \mathrm{ng} / \mathrm{mL}$ EGF group. The terminal weight of the NEC group, NEC + $50 \mathrm{ng} / \mathrm{mL}$ EGF group, and NEC $+1,000 \mathrm{ng} / \mathrm{mL}$ EGF group decreased to different degrees compared with birth weight $(\mathrm{P}<0.05)$. The weight loss of the NEC $+1,000 \mathrm{ng} / \mathrm{mL}$ EGF group was smaller than that of the NEC group and the NEC $+50 \mathrm{ng} / \mathrm{mL}$ EGF group $(\mathrm{P}<0.01)$. There was no significant difference in weight loss between the NEC group and the NEC + $50 \mathrm{ng} / \mathrm{mL}$ EGF group (Table 1).

\section{EGF at a dose of $500 \mathrm{ng} / \mathrm{mL}$ can effectively protect intestinal tissue}

The intestinal tissue of the control group was normal in appearance, having no necrosis, being bright in color, not easily broken, and complete (Figure $1 A$ ), while in the NEC group the large intestinal tissue was severely necrotic, fragile, and incomplete (Figure $1 B$ ). However, after exogenous EGF supplementation, the area of intestinal tissue necrosis decreased, integrity increased, and brittleness decreased (Figure 1C,D,E). The intestine tissue in the NEC $+50 \mathrm{ng} / \mathrm{mL}$ EGF group was still necrotic and incomplete (Figure 1C) and in the NEC $+500 \mathrm{ng} / \mathrm{mL}$ EGF group and $\mathrm{NEC}+1,000 \mathrm{ng} / \mathrm{mL}$ EGF group the tissue was complete but still necrotic (Figure 1D,E). There was a nonsignificant difference between intestinal tissue appearance in the $\mathrm{NEC}+500 \mathrm{ng} / \mathrm{mL}$ EGF group and NEC + $1000 \mathrm{ng} / \mathrm{mL}$ EGF group (Figure 1D,E). This suggested that oral supplementation with EGF could reduce the severity of intestinal injury in the NEC rat model.

Before sacrifice, rats in the NEC group were extremely thin, had pale, lax, and dehydrated skin, and decreased alertness, requiring strong stimulation to respond. Most of these rats were in the supine position, had less writhing than others, and some developed wheezing. After the oral administration of exogenous EGF, the physiological status of the rats improved. They were only slightly weak, had a ruddy complexion, good skin elasticity, and moved normally. 
A
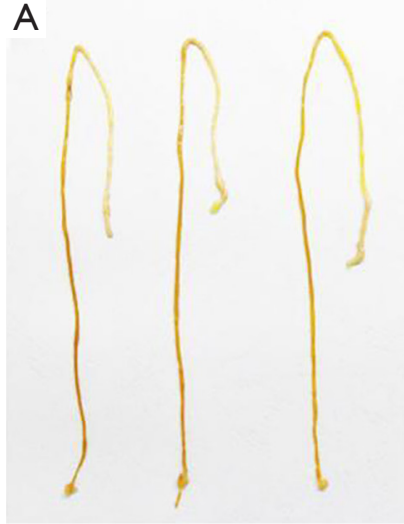

D

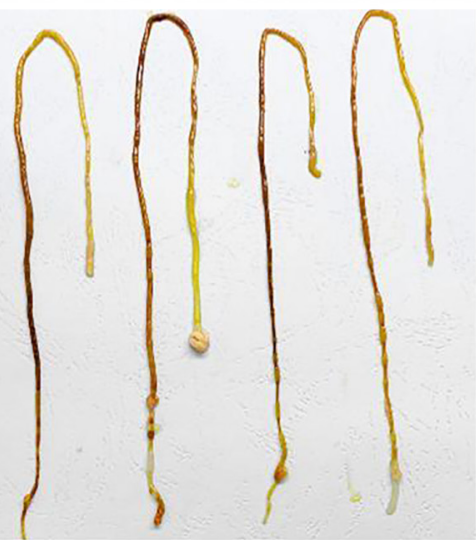

B
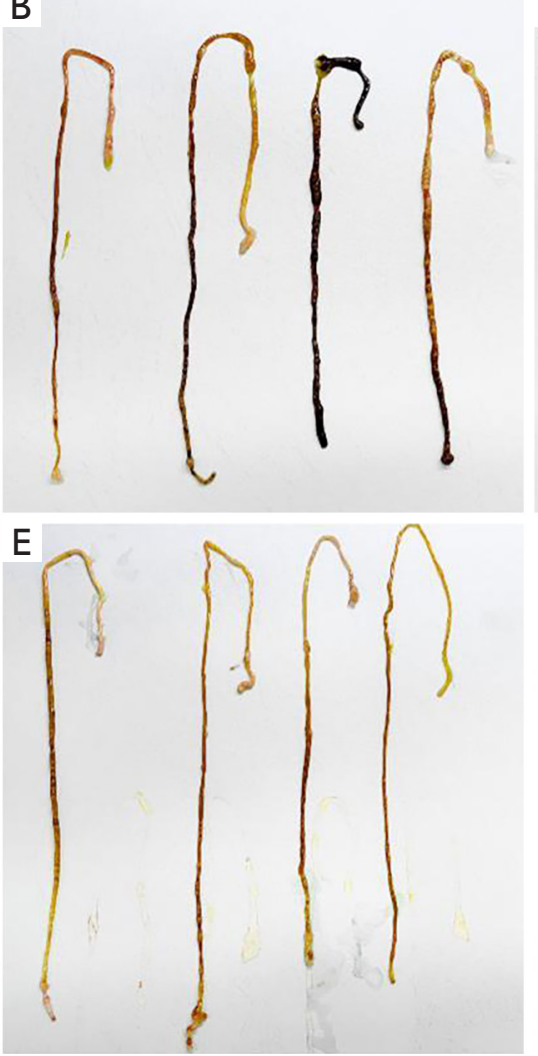

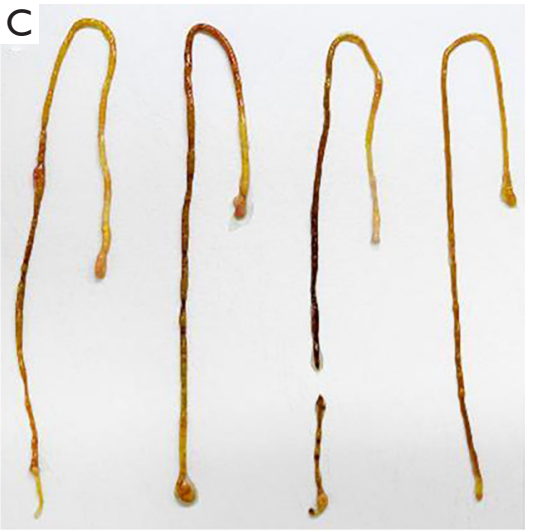

Figure 1 Intestinal tissue appearance. (A) The intestinal tissue of the control group was normal in appearance; (B) the NEC group intestine was severely necrotic, and the tissue was fragile and incomplete; $(\mathrm{C})$ the $\mathrm{NEC}+50 \mathrm{ng} / \mathrm{mL}$ EGF group intestinal tissue showed extensive necrosis, and the tissue was fragile and incomplete; (D) the NEC + $500 \mathrm{ng} / \mathrm{mL}$ EGF group intestinal tissue; (E) the NEC + 1,000 ng/ $\mathrm{mL}$ EGF group intestinal tissue. Intestinal tissue in (D) and (E) showed patchy necrosis, and the tissue was complete. NEC, Necrotizing enterocolitis; EGF, epidermal growth factor.

The physiological scores of each group were: $0(0,1.0)$ in the control group, $4.0(4.0,8.0)$ in the NEC group, 3.5 $(3.0,4.0)$ in the NEC+50 ng/ml EGF group, $2.5(0,4.0)$ in the NEC+1,000 ng/mL EGF group, and $0.5(0,1.0)$ the $\mathrm{NEC}+500 \mathrm{ng} / \mathrm{mL}$ EGF group. The physiological score of the NEC group was significantly higher than that of the control group $(\mathrm{P}<0.0001)$. The $\mathrm{NEC}+500 \mathrm{ng} / \mathrm{mL}$ EGF group and NEC $+1,000 \mathrm{ng} / \mathrm{mL}$ EGF group had significantly lower physiological scores than the NEC group $(\mathrm{P}<0.01)$, and the NEC $+500 \mathrm{ng} / \mathrm{mL}$ EGF group had significantly lower physiological scores than the NEC + 1,000 ng/mL EGF group $(\mathrm{P}<0.05)$. This suggested that additional oral administration of $500 \mathrm{ng} / \mathrm{mL}$ and $1,000 \mathrm{ng} / \mathrm{mL}$ EGF could significantly improve the physiological status of NEC rats, and $500 \mathrm{ng} / \mathrm{mL}$ had a better performance (Figure 2).

The results of HE staining showed that the intestinal tissue structure of the control group was clear and normal, the epithelium was continuous, and the glands were arranged regularly. The villi were soaring, and there was no hyperemic edema or detachment in the mucosa layer, submucosa, or lamina propria. By contrast the NEC group had severe intestinal tissue necrosis and disorderly arranged glands, and some glands had disappeared. Villus degeneration and edema unevenness appeared, part of the villous necrosis shed or disappeared, the muscle layer became thin or even broken, and severe edema of the lamina propria and submucosa could be seen. However, after oral administration of EGF, the degree of separation between the submucosa and the propria of the intestine was reduced, the degree of edema was reduced, and there was no obvious necrosis and shedding of the villi (Figure 3).

The pathological scores of each group were: $0.5(0,1.0)$ in the control group, $3.5(3.0,4.0)$ in the NEC group, 2.5 $(2.0,3.0)$ in the NEC $+50 \mathrm{ng} / \mathrm{mL}$ EGF group, $0.75(0,2.0)$ in 


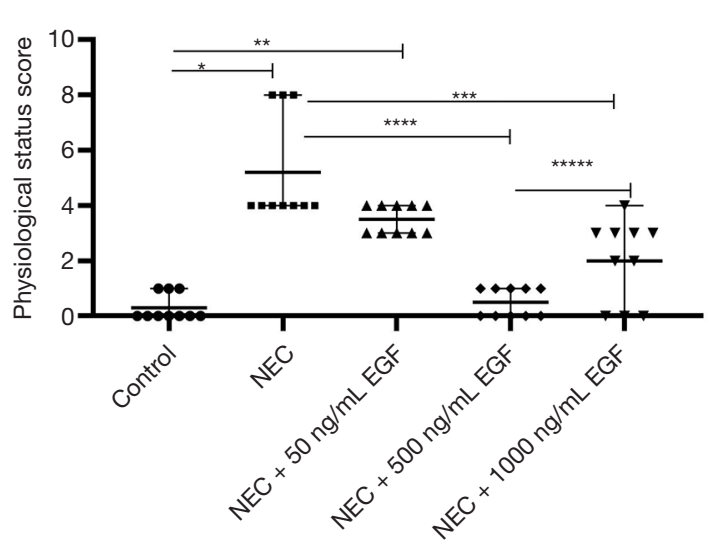

Figure 2 Physiological status score. ${ }^{*} \mathrm{P}<0.0001$ for the control group versus the NEC group, ${ }^{*} \mathrm{P}<0.001$ for the control group versus the $\mathrm{NEC}+50 \mathrm{ng} / \mathrm{mL}$ EGF group, ${ }^{* * *} \mathrm{P}<0.01$ for the NEC group versus the $\mathrm{NEC}+1,000 \mathrm{ng} / \mathrm{mL}$ EGF group, ${ }^{* * * *} \mathrm{P}<0.0001$ for the NEC group versus the NEC + $500 \mathrm{ng} / \mathrm{mL}$ EGF group, $* * * * * \mathrm{P}<0.05$ for the $\mathrm{NEC}+500 \mathrm{ng} / \mathrm{mL}$ EGF group versus the $\mathrm{NEC}+1,000 \mathrm{ng} / \mathrm{mL}$ EGF group. Data are presented as the median (minimum, maximum). NEC, Necrotizing enterocolitis; EGF, epidermal growth factor.

the NEC $+500 \mathrm{ng} / \mathrm{mL}$ EGF group, and $1.25(0,2.0)$ in the $\mathrm{NEC}+1,000 \mathrm{ng} / \mathrm{mL}$ EGF group. There was no significant difference in pathological score between the NEC $+50 \mathrm{ng} / \mathrm{mL}$ EGF group and the NEC group. The pathological scores of the NEC + $500 \mathrm{ng} / \mathrm{mL}$ EGF group and the NEC + $1,000 \mathrm{ng} / \mathrm{mL}$ EGF group were significantly lower than those of the NEC group $(\mathrm{P}<0.001)$. The pathological score of the NEC $+500 \mathrm{ng} / \mathrm{mL}$ EGF group was slightly lower than that of the $\mathrm{NEC}+1,000 \mathrm{ng} / \mathrm{mL}$ EGF group, but there was no significant difference between them $(\mathrm{P}=0.29)$. These findings suggest additional oral administration of $50 \mathrm{ng} / \mathrm{mL}$ EGF could not reduce the incidence of NEC and the severity of tissue damage. Oral $500 \mathrm{ng} / \mathrm{mL}$ and $1,000 \mathrm{ng} / \mathrm{mL}$ EGF can significantly reduce the incidence and severity of NEC, and there is no significant difference between the two doses (Figure 4). NEC was considered to have occurred when the pathological score $\geq 2$. The number of NEC cases in each group was 0 in the control group (0\%), 10 in the NEC group $(100 \%), 10$ in the NEC $+50 \mathrm{ng} / \mathrm{mL}$ group $(100 \%)$, one case $(10 \%)$ in the $\mathrm{NEC}+500 \mathrm{ng} / \mathrm{mL}$ group, and three cases $(30 \%)$ in the NEC+1000 $\mathrm{ng} / \mathrm{mL}$ group. There was no significant difference in NEC incidence between the NEC $+500 \mathrm{ng} / \mathrm{mL}$ EGF group and the NEC + 1,000 ng/mL EGF group (Fisher's exact method, $\mathrm{P}=0.58$ ).

\section{EGF at a dose of $500 \mathrm{ng} / \mathrm{mL}$ effectively reduced inflammation factors levels in intestinal tissue}

The levels of IL-1 $\beta$ and IL- 6 in the intestinal mucosa of the control group were significantly lower than those in the NEC group $(\mathrm{P}<0.0001)$, as shown in Table 2. In the NEC + $50 \mathrm{ng} / \mathrm{mL}$ EGF group IL-1 $\beta$ and IL-6 were insignificantly different from the NEC group $(\mathrm{P}>0.05)$. Compared with NEC group, and NEC $+50 \mathrm{ng} / \mathrm{mL}$ EGF group, the $\mathrm{NEC}+500 \mathrm{ng} / \mathrm{mL}$ EGF group and NEC + 1,000 ng/mL EGF group had significant lower levels in IL-1 $\beta$ and IL-6 $(\mathrm{P}<0.001)$. The levels of IL-1 $\beta$ and IL-6 in the intestinal mucosa of the NEC $+500 \mathrm{ng} / \mathrm{mL}$ EGF group were significantly lower than those in the NEC $+1,000 \mathrm{ng} / \mathrm{mL}$ EGF group $(\mathrm{P}<0.05)$.

\section{Results of high-throughput transcriptome sequencing}

Compared with the $500 \mathrm{ng} / \mathrm{mL}$ EGF group, the NEC group had a total of 1,767 significantly differentially expressed genes, of which 397 differential genes are involved in regulating tissue growth, apoptosis, inflammation, barrier function, and tissue perfusion. The GO cell component analysis of the cell location where these genes were located indicated there was a significant enrichment of differential genes on the cell surface, cell membrane, cell junction, and other components (Figure 5). Further selection of differential genes at cell junctions for the KEGG pathway analysis suggested that significant differential genes were mainly involved in the coding of tight junction-related proteins between cells (Figure 6). Further, the expression of claudin 3 (Gene ID: 65130) in the EGF group was significantly increased [ $\log 2$ (EGF/ $\mathrm{NEC)}=1.498, \mathrm{Q}=0$ ].

EGF inhibited the expression of some pro-apoptotic proteins in the apoptosis pathway (Figure 7). Compared with the NEC group, the gene expression of fal-L, caspases-3, caspases-7, bak, cytC (cytochrome C), PIDD, and other pro-apoptotic molecules in the $500 \mathrm{ng} / \mathrm{ml} \mathrm{EGF}$ group decreased, indicating that EGF inhibited cell apoptosis. Compared with the NEC group, the pro-inflammatory factor IL-31R $\alpha$ in the EGF group was significantly reduced $[\log 2(\mathrm{EGF} / \mathrm{NEC})=-2.090, \mathrm{Q}=4.478 \mathrm{e}-4]$, while the expression of the inflammation inhibitory factors S100A9 and S100A8 increased, respectively $\log 2(\mathrm{EGF} / \mathrm{NEC})$ $=1.465, \mathrm{Q}=1.197 \mathrm{e}-77$ and $\log 2(\mathrm{EGF} / \mathrm{NEC})=1.405$, $\mathrm{Q}=1.119 \mathrm{e}-35$. 
A
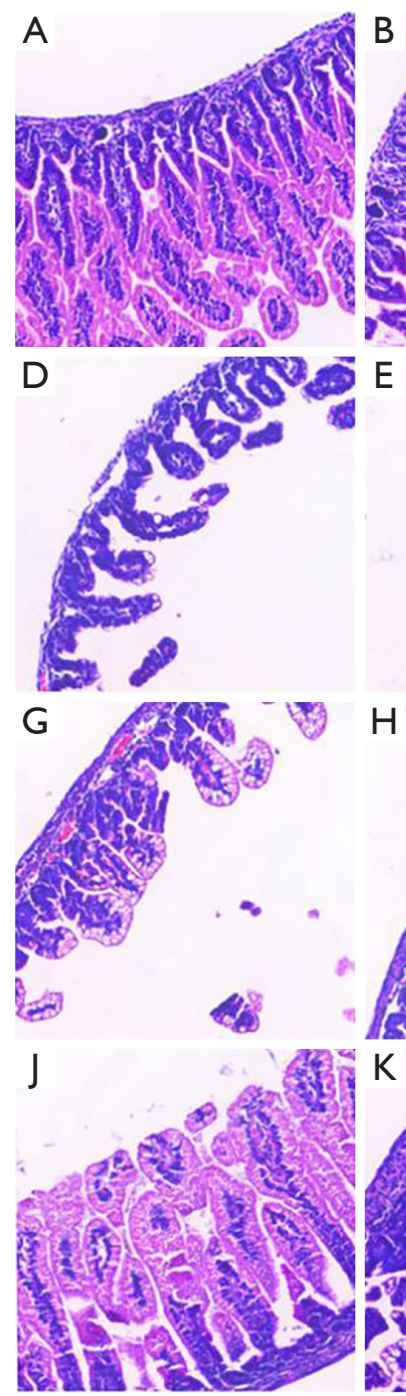

M

$\mathrm{N}$

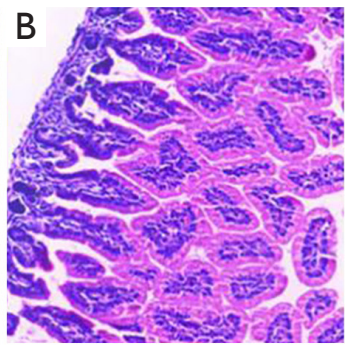

$E$

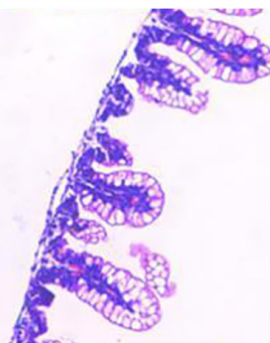

$\mathrm{H}$

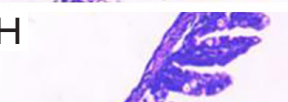

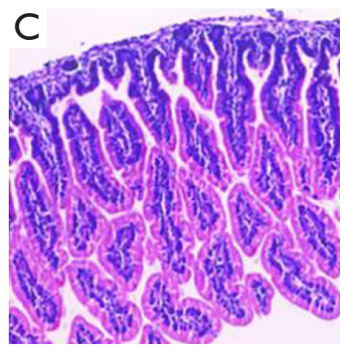

$\mathrm{F}$
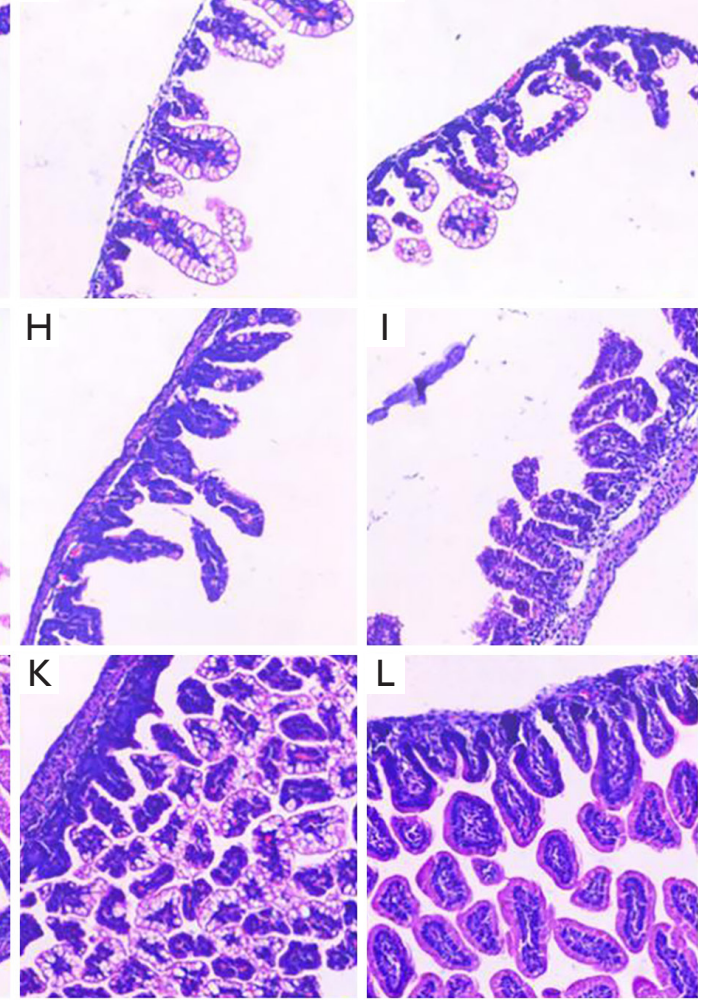

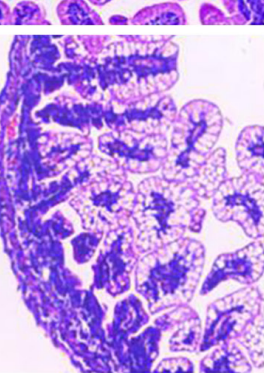

Figure 3 HE staining of the intestine (original magnification 200x). (A-C) The epithelium of the control group is continuous, and the glands are arranged regularly. The villi are soaring, and there is no hyperemic edema or detachment in the mucosa layer, submucosa, and lamina propria. (D-F) The NEC group has severe intestine necrosis and disorderly arranged glands and some glands have disappeared. Villus degeneration and edema unevenness are present, part of the villous necrosis has shed or disappeared, the muscle layer has become thin or even broken, and severe edema of the lamina propria and submucosa can be seen. (G-I) The NEC $+50 \mathrm{ng} / \mathrm{mL}$ EGF group shows disorderly arranged glands and severe separation of the submucosa and lamina propria, edema in the submucosa and muscular layers, and region villous sloughing. (J-L) The NEC $+500 \mathrm{ng} / \mathrm{mL}$ EGF group has no edema or detachment in the mucosa layer, submucosa, and lamina propria. (MO) The NEC + 1,000 $\mathrm{ng} / \mathrm{mL}$ EGF group has slight separation in the mucosa layer, but no edema in the submucosa and lamina propria. HE, hematoxylin-eosin; NEC, Necrotizing enterocolitis; EGF, epidermal growth factor. 


\section{Discussion}

NEC is a serious gastrointestinal disease in the neonatal period which mostly occurs in preterm infants, and the younger the gestational age, the higher the morbidity and mortality (1). While NEC is currently believed to be related to factors such as preterm birth, artificial feeding, and hypoxia (30), these factors do not play a separate role in the pathogenesis of NEC but are related and promote each other. Therefore, single-factor modeling is not consistent with the clinical pathogenesis and in this study, based on

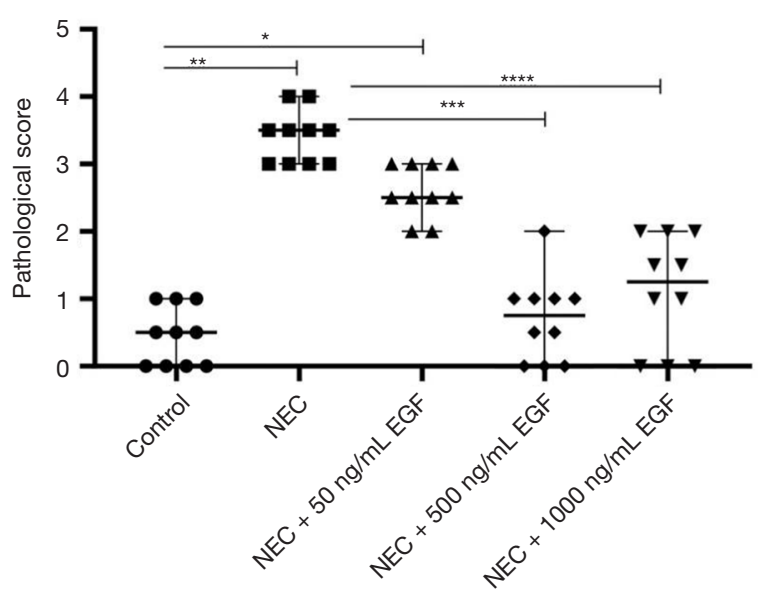

Figure 4 Intestinal pathological score. ${ }^{*} \mathrm{P}<0.01$ for the control group versus the $\mathrm{NEC}+50 \mathrm{ng} / \mathrm{mL}$ EGF group, ${ }^{* *} \mathrm{P}<0.0001$ for the control group versus the NEC group, ${ }^{* * *} \mathrm{P}<0.0001$ for the NEC group versus the $\mathrm{NEC}+500 \mathrm{ng} / \mathrm{mL}$ EGF group, ${ }^{* * *} \mathrm{P}<0.001$ for the NEC group versus the NEC + 1,000 ng/mL EGF group. NEC, Necrotizing enterocolitis; EGF, epidermal growth factor. the pathogenic factors of NEC, a multi-factor method was used to establish the NEC model. Under the stimulation of hypoxia and cold, symptoms such as weight loss, paleness, decreased activity, and decreased response to stimulation were found in artificially feeding premature rats in the NEC model group. Large intestinal necrosis occurred, and the tissue was fragile and incomplete. Compared with the control group, the intestinal pathological score was significantly higher. These findings are consistent with the clinical manifestations and pathology of NEC in neonates, suggesting the successful establishment of NEC models.

The fetus is immersed in amniotic fluid in the womb and swallows a large amount of amniotic fluid daily. The concentration of growth factors in the amniotic fluid gradually increases with the gestational week, and the concentration of growth factors reaches its peak at term (31). Therefore, it is speculated that the prevalence of NEC in preterm infants is higher than that in term infants. It may be that premature infants leave the mother prematurely, which reduces the stimulation of EGF in amniotic fluid to the intestine, leading to immature intestinal development. The source of neonatal EGF is mainly from breast milk. Contrary to the level of EGF in amniotic fluid, the level of EGF in breast milk peaks on the first day after delivery (approximately $100 \mathrm{ng} / \mathrm{mL}$ ) and gradually decreases within 1 month after birth. The content of EGF in the milk of mothers of very preterm infants is $50 \%$ to $80 \%$ higher than that of mothers of term infants (32). Although the physiological significance of this phenomenon is not completely clear, elevated EGF levels in breast milk may be the underlying reason for the protective effect of breast milk on NEC. Comparison of the levels of EGF in amniotic

Table 2 Levels of inflammatory factors in the intestinal tissue

\begin{tabular}{lccc}
\hline Groups & Cases & IL-1 $\beta$ (ng/L) & IL-6 (ng/L) \\
\hline control & 10 & $269.25 \pm 43.56$ & $214.83 \pm 64.29$ \\
NEC & 10 & $382.54 \pm 24.23^{\mathrm{a}}$ & $490.22 \pm 39.42^{\mathrm{a}}$ \\
$\mathrm{NEC}+50 \mathrm{ng} / \mathrm{mL}$ EGF & 10 & $358.36 \pm 35.23^{\mathrm{a}}$ & $430.53 \pm 82.35^{\mathrm{a}}$ \\
$\mathrm{NEC}+500 \mathrm{ng} / \mathrm{mL}$ EGF & 10 & $272.67 \pm 52.71^{\mathrm{b}, \mathrm{c}}$ & $265.49 \pm 51.84^{\mathrm{b}, \mathrm{c}}$ \\
NEC $+1,000 \mathrm{ng} / \mathrm{mL}$ EGF & 10 & $308.23 \pm 38.33^{\mathrm{a}, \mathrm{b}, \mathrm{c}, \mathrm{d}}$ & $316.55 \pm 48.41^{\mathrm{a}, \mathrm{b}, \mathrm{c}, \mathrm{d}}$ \\
F value & & 19.257 & 33.241 \\
P value & & $<0.0001$ & $<0.0001$ \\
\hline
\end{tabular}

Data are presented as the mean $\pm \mathrm{SD}$. ${ }^{\mathrm{a}} \mathrm{P}<0.0001$, compared with the control group. ${ }^{b} \mathrm{P}<0.0001$, compared with the NEC group. ${ }^{\mathrm{C}} \mathrm{P}<0.001$, compared with the NEC $+50 \mathrm{ng} / \mathrm{mL}$ EGF group $(P<0.05)$. ${ }^{d} P<0.05$, compared with the $\mathrm{NEC}+500 \mathrm{ng} / \mathrm{mL} E G F \mathrm{group}(\mathrm{P}<0.05)$. SD, standard deviation; NEC, necrotizing enterocolitis; EGF, epidermal growth factor. 
NEC vs. EGF GO cellular component Rich Bubble Chart

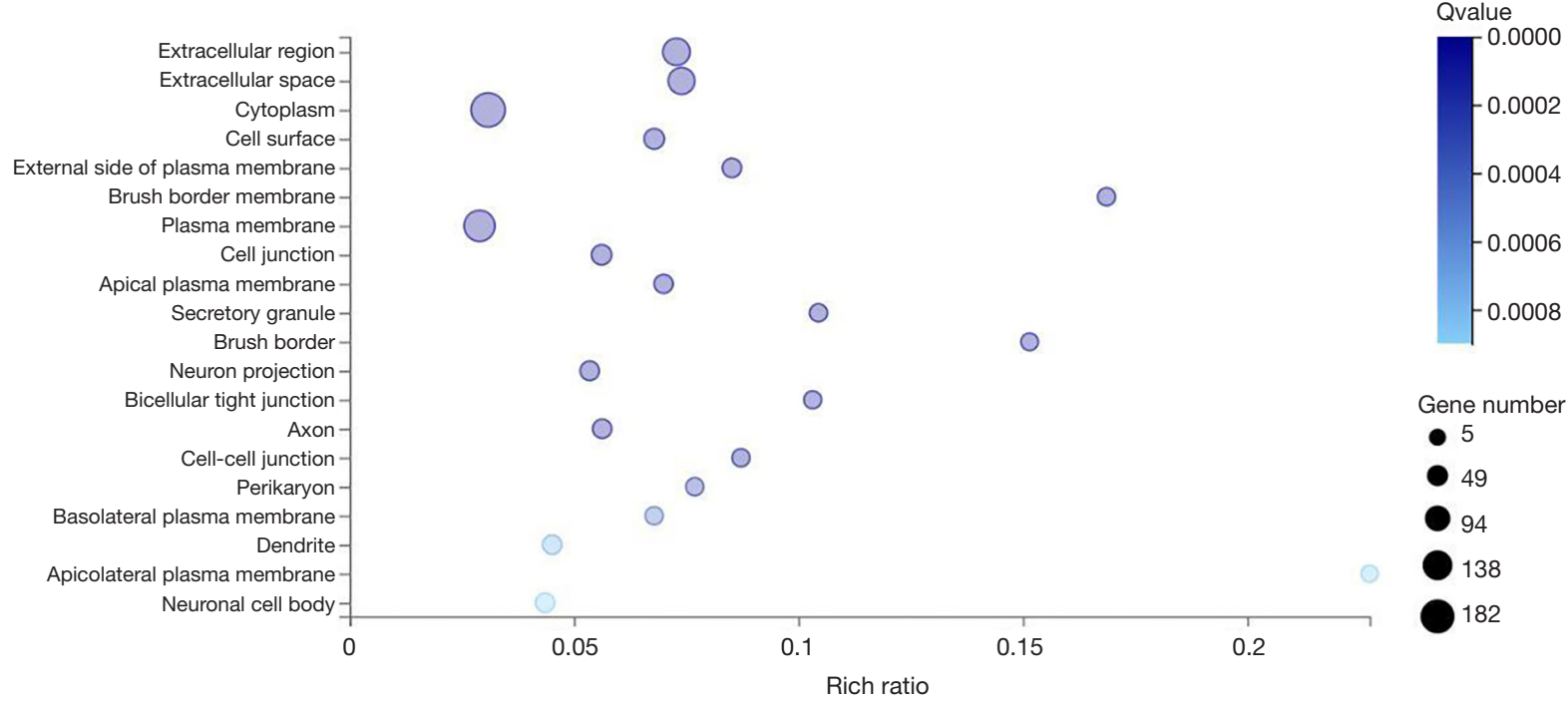

Figure 5 NEC vs. EGF GO cellular component rich bubble chart. The differentially expressed genes (DEGs) were significant enrichment on the cell surface, cell membrane and cell junction. NEC, Necrotizing enterocolitis; EGF, epidermal growth factor; GO, gene ontology; DEGs, differentially expressed genes.

NEC vs. EGF Cell junction KEGG pathway Rich Bar

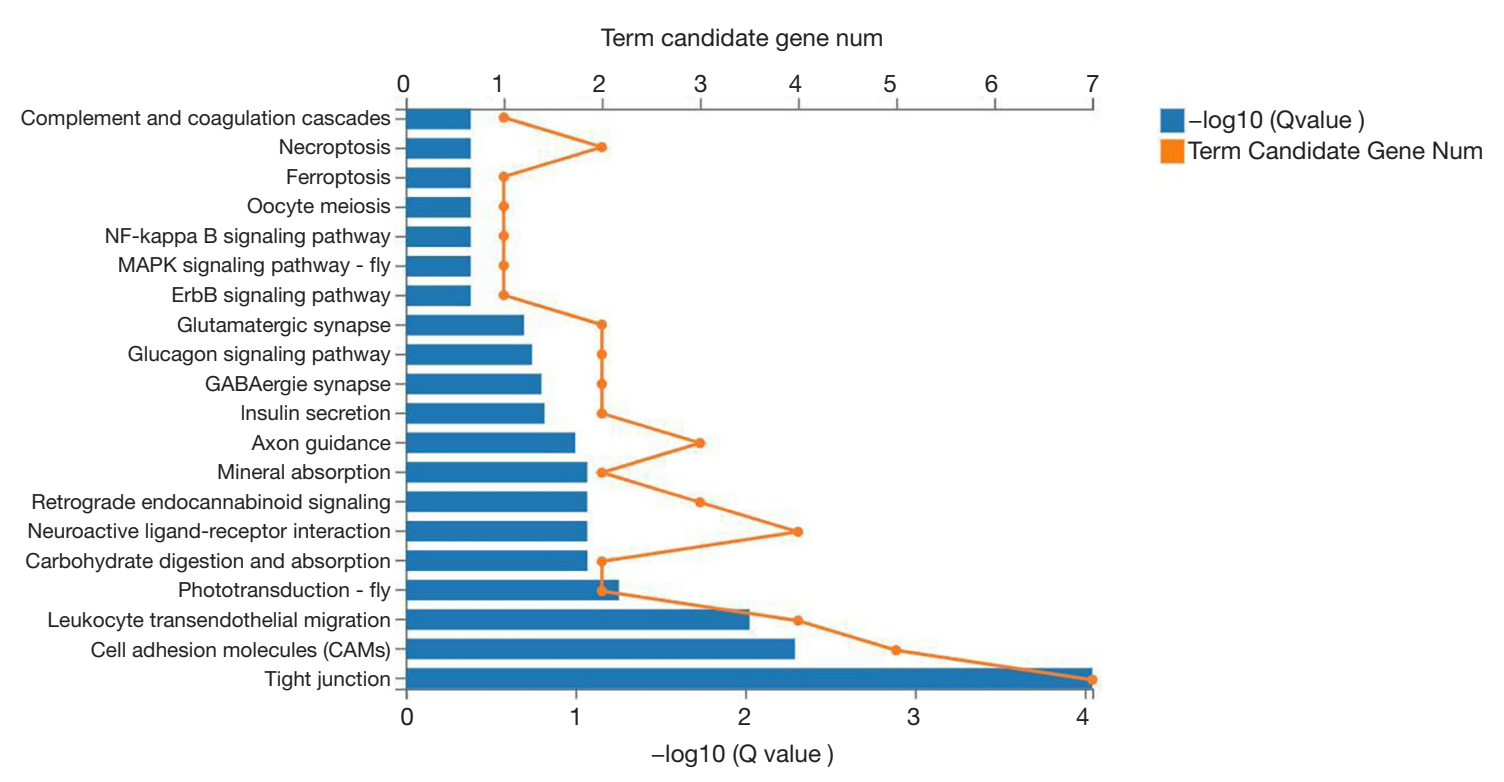

Figure 6 NEC $v s$. EGF cell junction KEGG pathway rich bar. The significant differential genes at cell junctions were mainly involved in the tight junction. NEC, Necrotizing enterocolitis; EGF, epidermal growth factor; KEGG, the Kyoto Encyclopedia of Genes and Genomes. 


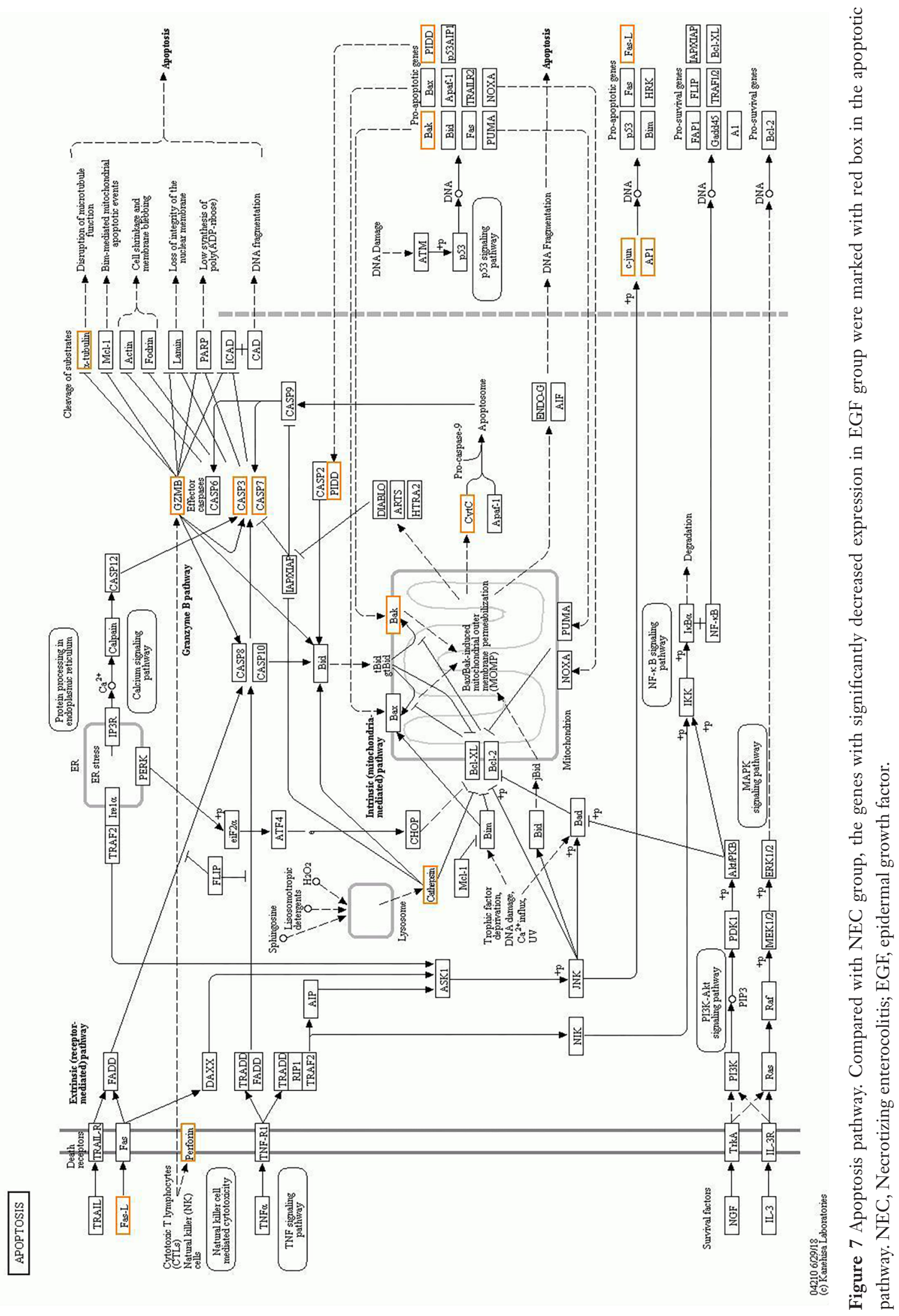


fluid and breast milk suggests that premature cessation or insufficient EGF exposure may be a high-risk factor for NEC. Cathy (33) and others studied the relationship between EGF levels in saliva and serum and NEC, and found that EGF in the serum and saliva of NEC patients was significantly reduced, suggesting that low levels of EGF are risk factors for NEC and related to its onset. In our study, additional EGF was added to rat milk substitutes, and the intestine was continuously exposed to the stimulation of EGF through oral administration. The NEC model was constructed through the process of hypoxia-cold stimulation to evaluate the prevention of NEC by EGF. Through experimental observation and comparison, it was found that the postnatal weight loss of rats after additional EGF supplementation was significantly lower than that of the NEC group, and the physiological scores and pathological scores of intestinal tissues in rats were significantly lower than those in the NEC group after additional $500 \mathrm{ng} / \mathrm{mL}$ EGF supplementation. This suggests additional EGF supplementation could effectively reduce the incidence of NEC and the severity of the disease, which is consistent with the results of Dvorak et al. (34).

There are few related studies on the dose of EGF required for the prevention of NEC. While the milk of normal rats contains 30-50 ng/mL EGF (35), in our study there was no control effect on the NEC model when only $50 \mathrm{ng} / \mathrm{mL}$ EGF was taken orally. However, when the dose was increased to $500 \mathrm{ng} / \mathrm{mL}$ EGF, the incidence and severity of NEC were significantly reduced. This may be because EGF is a small molecule polypeptide and can be hydrolyzed by proteases when passing through the gastrointestinal tract. Breast milk contains a variety of proteins with enzyme inhibitor activity, such as casein, which can bind to specific proteases and competitively inhibit the activity of proteases, thereby reducing the degradation of EGF in the gastrointestinal tract (36). Therefore, the exogenous EGF supplement dose should be higher than the physiological dose to offset protein decomposition. In addition, the biological efficacy of EGF mainly depends on the expression of the epidermal growth factor receptor (EGFR). Good (14) and others have found that breast milk can prevent and reduce the incidence of NEC and the growth factor component in breast milk is the main substance that plays this role by activating EGFR in the intestinal epithelium. Further, by removing EGF in breast milk or blocking EGFR in the intestinal epithelium, the protective effect of breast milk on NEC is obviously eliminated. EGFR is the main receptor for the biological function of EGF, and EGF is the transcriptional regulator of EGFR. EGF can increase EGFR gene transcription in liver cells twofold, at the same time increasing the level and stability of EGFR mRNA (37). A study on the adaptive regeneration process of intestinal tissue after intestinal resection found that the submandibular gland of experimental rats was cut off to block endogenous EGF secretion, and the expression of EGFR in the intestinal mucosa was reduced, thereby inhibiting the adaptive regeneration process. However, after exogenous EGF supplementation, the expression of EGFR in the intestinal mucosa significantly increased, and the adaptive regeneration process reappeared (38). These findings suggest an extra dose of EGF given above the physiological dose can stimulate the expression of intestinal EGFR, and the combination of EGF with EGFR can amplify the biological role of EGF, thereby reducing intestinal damage. In our study, there was no significant difference in the protective effect when the dose of EGF increased from $500 \mathrm{ng} / \mathrm{mL}$ to $1,000 \mathrm{ng} / \mathrm{mL}$. This may be because the intestinal mucosal surface was completely saturated with EGFR as when EGFR is fully bound to EGF, even if there is excess EGF, it cannot perform its biological functions due to the lack of corresponding receptors.

Transcriptome sequencing can detect all the transcript information of tissue in different physiological states (39), providing a new technical means for examining the pathogenesis of NEC and the mechanism of EGF. In our study, the NEC group and the NEC + $500 \mathrm{ng} / \mathrm{mL}$ EGF group were compared with the expression levels of significantly different genes in the intestinal tissues and GO and KEGG analyses were performed to initially reveal the possible protective mechanism of EGF on NEC. The KEGG pathway analysis of differential genes located at cell junctions suggested EGF would significantly change the expression of cell tight junction proteins. Among them, the expression of claudin 3 in the EGF group was significantly increased, suggesting that additional EGF feeding can significantly increase its expression in the intestinal epithelium. This increase is conducive to maintaining the barrier function of the intestinal epithelium, ensuring the integrity and permeability of the epithelium, and reducing NEC. Claudin protein is an important protein involved in tight junctions and has the effect of regulating the permeability of the intestine and the selectivity of material transport (40). Shim (41) studied the effect of radiation on intestinal barrier function and found that the expression of claudin 3 was significantly decreased when the intestinal barrier was damaged, and expression was significantly 
increased after corresponding treatments which also improved intestinal barrier function. Claudin 3 can be used as a marker of intestinal injury. By comparing the expression of differential genes between the EGF group and the NEC group in the apoptosis pathway, we found that additional oral EGF inhibited fal-L, caspases-3, caspases-7, bak, cytC (cytochrome C), PIDD, and other pro-apoptosis molecular expressions. Compared with the NEC group, the proinflammatory factor interleukin 31 receptor alpha (IL-31R $\alpha$ ) in the EGF group was significantly reduced. IL-31R $\alpha$ is a strong pro-inflammatory factor, and its combination with IL-31 leads to phosphorylation and activation of STATs, MAPK, and JNK signaling pathways, causing a strong tissue inflammatory response and the appearance of allergic diseases (42). Studies have found that bone marrow-derived suppressor cells (MDSCs) can inhibit the inflammatory response of NEC, mainly by promoting the expression of anti-inflammatory factors S100A9 and S100A8 (43). In our study, we compared the expression of S100A9 and S100A8 between EGF and NEC groups and found EGF could significantly increase the expression levels of S100A9 and S100A8 to inhibit inflammation. By comparing the expression levels of IL- 6 and IL-1 $\beta$, we also found that the $500 \mathrm{ng} / \mathrm{mL}$ dose of EGF had the most significant inhibitory effect on intestinal inflammation. The results of high-throughput transcriptome sequencing confirmed that the expression of IL-31R $\alpha$, S100A9, and S100A8 may be evidence that EGF exerts an inhibitory effect on inflammation.

There are some limitations to this study. Although the protective effect of $500 \mathrm{ng} / \mathrm{mL}$ EGF on NEC is obvious, we speculate that the most appropriate dose may be between 500 and $1,000 \mathrm{ng} / \mathrm{mL}$. However, the dose gradient to clarify the most appropriate dose was not established. Moreover, the mechanism by which the $1,000 \mathrm{ng} / \mathrm{mL}$ dose of EGF was weaker than the $500 \mathrm{ng} / \mathrm{mL}$ dose on NEC is not clear. The analysis of high-throughput sequencing results suggests EGF effects the intestinal barrier, apoptosis, and inflammation of the NEC intestine. However, this study did not conduct laboratory verification and in future studies, we will try to establish the detailed mechanism by which EGF effects the intestinal tract of NEC.

\section{Conclusions}

In this study, differences in the protective effects of different doses of EGF were analyzed. The $500 \mathrm{ng} / \mathrm{mL}$ dose of EGF had the best protective effect on the intestines of NEC model rats. In the analysis of high-throughput sequencing results, we found that EGF may protect the intestinal tract of NEC model rats by regulating the intestinal barrier, apoptosis, and inflammation.

\section{Acknowledgments}

Funding: The research was funded by Youth Science Innovation Foundation of the Fujian Maternity and Child Health Hospital (grant number YCXQ 18-26).

\section{Footnote}

Reporting Checklist: The authors have completed the ARRIVE reporting checklist. Available at http://dx.doi. org/10.21037/tp-21-81

Data Sharing Statement: Available at http://dx.doi. org/10.21037/tp-21-81

Conflicts of Interest: All authors have completed the ICMJE uniform disclosure form (available at http://dx.doi. org/10.21037/tp-21-81). The authors have no conflicts of interest to declare.

Ethical Statement: The authors are accountable for all aspects of the work in ensuring that questions related to the accuracy or integrity of any part of the work are appropriately investigated and resolved. This study was performed according to international, national, and institutional rules considering animal experiments, clinical studies, and biodiversity rights. The study protocol was approved by the Ethics Committee of the Fujian Maternity and Child Health Hospital (EC Certificate No. 2018-195).

Open Access Statement: This is an Open Access article distributed in accordance with the Creative Commons Attribution-NonCommercial-NoDerivs 4.0 International License (CC BY-NC-ND 4.0), which permits the noncommercial replication and distribution of the article with the strict proviso that no changes or edits are made and the original work is properly cited (including links to both the formal publication through the relevant DOI and the license). See: https://creativecommons.org/licenses/by-nc-nd/4.0/.

\section{References}

1. Denning NL, Prince JM. Neonatal intestinal dysbiosis in 
necrotizing enterocolitis. Mol Med 2018;24:4.

2. Ma F, Li S, Gao X, et al. Interleukin-6-mediated CCR9(+) interleukin-17-producing regulatory $\mathrm{T}$ cells polarization increases the severity of necrotizing enterocolitis. EBioMedicine 2019;44:71-85.

3. Patel RM, Kandefer S, Walsh MC, et al. Causes and timing of death in extremely premature infants from 2000 through 2011. N Engl J Med 2015;372:331-40.

4. Nino DF, Sodhi CP, Hackam DJ. Necrotizing enterocolitis: new insights into pathogenesis and mechanisms. Nat Rev Gastroenterol Hepatol 2016;13:590-600.

5. Bellodas Sanchez J, Kadrofske M. Necrotizing enterocolitis. Neurogastroenterol Motil 2019;31:e13569.

6. Lindberg TP, Caimano MJ, Hagadorn JI, et al. Preterm infant gut microbial patterns related to the development of necrotizing enterocolitis. J Matern Fetal Neonatal Med 2020;33:349-58.

7. Neu J. Necrotizing Enterocolitis: A Multi-omic Approach and the Role of the Microbiome. Dig Dis Sci 2020;65:789-96.

8. Van Belkum M, Mendoza Alvarez L, Neu J. Preterm neonatal immunology at the intestinal interface. Cell Mol Life Sci 2020;77:1209-27.

9. Knell J, Han SM, Jaksic T, et al. Current Status of Necrotizing Enterocolitis. Curr Probl Surg 2019;56:11-38.

10. Li X, Li X, Shang Q, et al. Fecal microbiota transplantation (FMT) could reverse the severity of experimental necrotizing enterocolitis (NEC) via oxidative stress modulation. Free Radic Biol Med 2017;108:32-43.

11. Drucker NA, McCulloh CJ, Li B, et al. Stem cell therapy in necrotizing enterocolitis: Current state and future directions. Semin Pediatr Surg 2018;27:57-64.

12. Mihi B, Good M. Impact of Toll-Like Receptor 4 Signaling in Necrotizing Enterocolitis: The State of the Science. Clin Perinatol 2019;46:145-57.

13. Gephart SM, Quinn MC. Relationship of Necrotizing Enterocolitis Rates to Adoption of Prevention Practices in US Neonatal Intensive Care Units. Adv Neonatal Care 2019;19:321-32.

14. Good M, Sodhi CP, Egan CE, et al. Breast milk protects against the development of necrotizing enterocolitis through inhibition of Toll-like receptor 4 in the intestinal epithelium via activation of the epidermal growth factor receptor. Mucosal Immunol 2015;8:1166-79.

15. Clark JA, Doelle SM, Halpern MD, et al. Intestinal barrier failure during experimental necrotizing enterocolitis: protective effect of EGF treatment. Am J Physiol Gastrointest Liver Physiol 2006;291:G938-49.
16. Clark JA, Lane RH, Maclennan NK, et al. Epidermal growth factor reduces intestinal apoptosis in an experimental model of necrotizing enterocolitis. Am J Physiol Gastrointest Liver Physiol 2005;288:G755-62.

17. Halpern MD, Dominguez JA, Dvorakova K, et al. Ileal cytokine dysregulation in experimental necrotizing enterocolitis is reduced by epidermal growth factor. J Pediatr Gastroenterol Nutr 2003;36:126-33.

18. Sullivan PB, Brueton MJ, Tabara ZB, et al. Epidermal growth factor in necrotising enteritis. Lancet 1991;338:53-4.

19. Sullivan PB, Lewindon PJ, Cheng C, et al. Intestinal mucosa remodeling by recombinant human epidermal growth factor(1-48) in neonates with severe necrotizing enterocolitis. J Pediatr Surg 2007;42:462-9.

20. Isani M, Illingworth L, Herman E, et al. Soybean-derived recombinant human epidermal growth factor protects against experimental necrotizing enterocolitis. J Pediatr Surg 2018;53:1203-7.

21. Zani A, Cordischi L, Cananzi M, et al. Assessment of a neonatal rat model of necrotizing enterocolitis. Eur J Pediatr Surg 2008;18:423-6.

22. Dvorak B, Khailova L, Clark JA, et al. Comparison of epidermal growth factor and heparin-binding epidermal growth factor-like growth factor for prevention of experimental necrotizing enterocolitis. J Pediatr Gastroenterol Nutr 2008;47:11-8.

23. Okogbule-Wonodi AC, Gross GW, Sun CC, et al. Necrotizing enterocolitis is associated with ureaplasma colonization in preterm infants. Pediatr Res 2011;69:442-7.

24. Wang Z, Gerstein M, Snyder M. RNA-Seq: a revolutionary tool for transcriptomics. Nat Rev Genet 2009;10:57-63.

25. Mortazavi A, Williams BA, McCue K, et al. Mapping and quantifying mammalian transcriptomes by RNA-Seq. Nat Methods 2008;5:621-8.

26. Love MI, Huber W, Anders S. Moderated estimation of fold change and dispersion for RNA-seq data with DESeq2. Genome Biol 2014;15:550.

27. Kanehisa M, Goto S. KEGG: kyoto encyclopedia of genes and genomes. Nucleic Acids Res 2000;28:27-30.

28. Ye J, Zhang Y, Cui H, et al. WEGO 2.0: a web tool for analyzing and plotting GO annotations, 2018 update. Nucleic Acids Res 2018;46:W71-w5.

29. Kanehisa M, Araki M, Goto S, et al. KEGG for linking genomes to life and the environment. Nucleic Acids Res 2008;36:D480-4. 
30. Rodrigo OD, Wood SK, Mejia MC, et al. Mortality from necrotizing enterocolitis: Greater racial inequalities and differences in risk factors. Pediatr Neonatol 2020;61:348-50.

31. Hofmann GE, Abramowicz JS. Epidermal growth factor (EGF) concentrations in amniotic fluid and maternal urine during pregnancy. Acta Obstet Gynecol Scand 1990;69:217-21.

32. Dvorak B, Fituch CC, Williams CS, et al. Increased epidermal growth factor levels in human milk of mothers with extremely premature infants. Pediatr Res 2003;54:15-9.

33. Shin CE, Falcone RA, Jr., Stuart L, et al. Diminished epidermal growth factor levels in infants with necrotizing enterocolitis. J Pediatr Surg 2000;35:173-6; discussion 7.

34. Dvorak B, Halpern MD, Holubec H, et al. Epidermal growth factor reduces the development of necrotizing enterocolitis in a neonatal rat model. Am J Physiol Gastrointest Liver Physiol 2002;282:G156-64.

35. Schaudies RP, Grimes J, Wray HL, et al. Identification and partial characterization of multiple forms of biologically active EGF in rat milk. Am J Physiol 1990;259:G1056-61.

36. Hesari A, Ghasemi F, Cicero AFG, et al. Berberine: A potential adjunct for the treatment of gastrointestinal cancers? J Cell Biochem 2018;119:9655-63.

37. Tajadura-Ortega V, Gambardella G, Skinner A, et al. O-linked mucin-type glycosylation regulates the

Cite this article as: Chen W, Yang C, Xue H, Huang Q. The protective effect and mechanism of epidermal growth factor on necrotizing enterocolitis in a neonatal rat model. Transl Pediatr 2021;10(4):900-913. doi: 10.21037/tp-21-81 transcriptional programme downstream of EGFR. Glycobiology 2021;31:200-10.

38. Knott AW, Erwin CR, Profitt SA, et al. Localization of postresection EGF receptor expression using laser capture microdissection. J Pediatr Surg 2003;38:440-5.

39. Ward DV, Scholz M, Zolfo M, et al. Metagenomic Sequencing with Strain-Level Resolution Implicates Uropathogenic E. coli in Necrotizing Enterocolitis and Mortality in Preterm Infants. Cell Rep 2016;14:2912-24.

40. Paquet-Fifield S, Koh SL, Cheng L, et al. Tight Junction Protein Claudin-2 Promotes Self-Renewal of Human Colorectal Cancer Stem-like Cells. Cancer Res 2018;78:2925-38.

41. Shim S, Lee JG, Bae CH, et al. Claudin-3 expression in radiation-exposed rat models: a potential marker for radiation-induced intestinal barrier failure. Biochem Biophys Res Commun 2015;456:351-4.

42. Edukulla R, Singh B, Jegga AG, et al. Th2 Cytokines Augment IL-31/IL-31RA Interactions via STAT6dependent IL-31RA Expression. J Biol Chem 2015;290:13510-20.

43. Liu Y, Perego M, Xiao Q, et al. Lactoferrin-induced myeloid-derived suppressor cell therapy attenuates pathologic inflammatory conditions in newborn mice. J Clin Invest 2019;129:4261-75.

(English Language Editor: B. Draper) 